\title{
For Onomatologists Only
}

With this issue we are instituting a column addressed especially to $A N S$ members in which we propose to discuss various items of interest to our group. We will include here significant information on the professional activities of our members - such as the publication of books and articles on names in other journals and the reading of onomatological papers before other societies - and such related news. (Popular items, such as brief notes and stories about names, will be printed elsewhere.) The emphasis in this column, then, will be on professional matters of some personal importance to the members of our Society. Contributions of this type will be gratefully received by E. Wallace McMullen, Associate Editor, Department of English, Lehigh University, Bethlehem, Pennsylvania.

\section{ONOMASTIC QUIZ}

Mr. Elsdon C. Smith contributed an article to the January 17, 1960, edition of Parade Magazine (p. 11; published with the Lincoln, Nebraska, Sunday Journal and Star) entitled "What Do Their Names Mean?" in which the public was challenged to match "words or phrases of origin" with the last names of twelve famous people who also were identified by photograph. The members of this select group were Dwight D. Eisenhower (German: saber-blade - an iron-hewer capable of shearing an iron nail); Helen Hayes (English: hedge-keeper); Yogi Berra (Italian: hut-dweller); Eleanor Roosevelt (Dutch: field of roses - one who lived by a veld of roses); Maria Callas (Greek: beautiful); Billy Graham (English-Scottish: gravel homestead); Debbie Reynolds (English: mighty power an early form of Reginald); Nikita Krushchev (Russian: beetle); Bernard Baruch (Hebrew: blessed); Grace Kelly (Irish: trouble); Admiral Hyman Rickover (German: mighty stream - from/ Reichau); and Arthur Godfrey (English: God's peace - the Norman form of the Old German Godafrid).

\section{GAFFNEY'S LAW}

Several newspapers throughout the UnitedStates-includingAlbuquerque, Omaha and San Francisco journals - carried stories about 
Professor Gaffney's theory of names which he presented in his paper, "A Potential Influence of Given Names on Character and Occupation," at the last annual $A N S$ meeting in Chicago. Miss Mamie Meredith writes that Gaffney's paper was printed on the editorial page of the St. Louis Post-Dispatch of January 10, 1960, "only slightly abridged, with $A N S$ mentioned prominently in the 3-line overhead. As illustrations, small pictures of a soldier with cap and a student in mortar board were used."

The December 30, 1959, issue of the Chicago Sun-Times put the story and a picture of Mr. Gaffney on the front page. Included in the fairly long summary is a statement of "Gaffney's first law of nomenclature," namely: "Your career is determined by your character and your character is determined perhaps unalterably by the name under which you grew to adulthood." Or stated more simply: "You are what your name has made you."

Professor Gaffney bases his theory on a forty-year analysis of thousands of names on U.S. Army rosters and on faculty listings in college catalogues. For example, he reported that among military officers there is a high proportion of terse, he-man names like Jack, Harry, Ned or Sam, all of which are complete given names, not shortened forms. College athletic coaches bear names like Don, Peter, and Lew. On the other hand, the majority of college faculty members have fancier names such as Grove Ettinger, Rizpah Anna, Sherlock Bronson, Lucius Adelno, Guy Redvers, and Fadra Homes. During the discussion which followed the reading of this paper Professor Kemp Malone mentioned a bishop named Noble Cilly Powell, and Professor Francis L. Utley observed that the president of Ohio State University is Novice (?) Fawcet. In this instance the theorist is an excellent illustration of his own theory: he is a professor of English at the University of Nebraska, and his name is Wilbur Geoffrey Gaffney.

\section{BIBLE BELT ONOMASTICS}

The February, 1960, issue of The William Feather Magazine (a monthly magazine in its forty-fourth year of publication, which is sent to "customers, prospects, and friends to let them know that we appreciate their business and goodwill") contains a digest of Thomas Pyles' article, "Bible Belt Onomastics," which was publi- 
shed in Names (Vol. VII, No. 2, June, 1959). Originally, as $A N S$ members will recall, this paper was given as the major address at our 1958 annual banquet meeting in New York.

\section{NAMES OF HURRICANES TO BE STANDARDIZED}

According to a UPI dispatch printed in the Lincoln, Nebraska, Evening Journal (January 29, 1960, p. 1614), the United States Weather Bureau has decided to standardize the names of hurricanes. Instead of digging up a brand new list of not previously used girls' names for the tropical storms each season, they are compiling four alphabetical sets of twenty-one names each of which should serve, with minor modifications, from this year on. At the end of every four years, they'll just start over.

$A N S$ readers will recall Erwin G. Gudde's article, "Naming Storms," which appeared in Names (Vol. III, No. 1, March, 1955). As Miss Mamie Meredith points out, this article attracted considerable popular attention.

E. W. M. 